\title{
Further promotion of "the JSH plan for the future" conscious of new normal after/with COVID-19: message from the new president of the Japanese Society of Hypertension
}

\author{
Hiromi Rakugi ${ }^{1}$
}

Published online: 5 January 2021

(c) The Japanese Society of Hypertension 2021

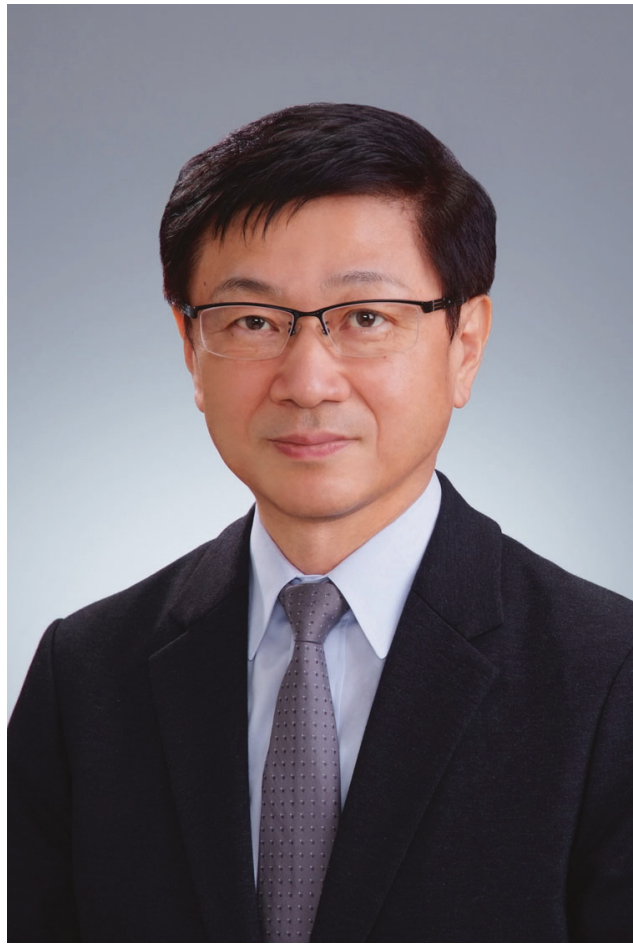

I was appointed as the new president of the Japanese Society of Hypertension (JSH) on October 26, 2020, succeeding President Hiroshi Ito. It is a great honor. During my 2-year term, I will push forward with the development of hypertension science and the development of hypertension treatment.

Hiromi Rakugi

rakugi@geriat.med.osaka-u.ac.jp

1 Department of Geriatric and General Medicine, Osaka University Graduate School of Medicine, Suita, Japan
The JSH established a "Future Plan" to conquer hypertension in 2018 with the slogan, "Good Blood Pressure for Lively 100 Years" [1, 2]. Our goal is to decrease the number of hypertensive individuals by seven million over the next decade, thereby extending healthy life expectancy. We had begun work to reach our goal, but the COVID-19 epidemic urged us to reconsider our plans. A keyword in this process is "new normal". Our "plan for the future" consists of three pillars; (1) medical care system, (2) academic research, and (3) social enlightenment. In each pillar, it is necessary to accelerate the promotion of the plan or build a new strategy with the awareness of "new normal".

\section{The first pillar of "the JSH plan for the future": medical care system}

We have planned to establish a lifetime-care system for individuals with hypertension via receiving high-quality hypertension care for all patients according to the guidelines and establishing a seamless hypertension care system led with a multidisciplinary network of hypertension specialists such as primary care physicians, medical teams, academic societies, administrative agencies, and insurance providers [3]. In the new normal era, furthermore, increased need for telemedicine is expected. In telemedicine, in addition to the development of a voice and image system that simulates face-to-face examination, construction of methods to accurately evaluate blood pressure and hypertension complications is also an important issue. Home blood pressure selfmeasurement is one solution in blood pressure assessment. Besides, academic research works described in the second section must be accelerated.

Another important issue in the medical system is dealing with major changes in lifestyle as a result of staying home and securing physical distance. These lifestyle changes to prevent COVID-19 infection lead to poor diet, poor exercise 
habits, and increased mental stress. As a result, increased salt intake, weight gain, and depression can occur. All these changes exacerbate hypertension. To prevent these, telemedicine only by doctors is not enough. A remote team medical system by multiple occupations should be constructed actively.

\section{The second pillar of "the JSH plan for the future": academic research}

We have planned to promote hypertension research which enables the prevention, prediction, and control of hypertension, by using artificial intelligence, big data, and telemedicine via the IoT. In the new normal era, this research field will become more and more important. In addition, I emphasize the importance of two new research fields for hypertension; bioinformatics and aging science.

Regarding bioinformatics, JSH held the 1st Digital Hypertension Conference in 2019 with Dr. Hiroshi Akazawa as chairman. Digital hypertension is a new science area that academically links new technologies (new devices, new technologies, new analysis methods) to create new strategies for hypertension care and healthcare [4]. Digital continuous data of blood pressure and heart rate have been investigated from various points of view such as a biomarker of sympathetic/parasympathetic nerve activities via frequency analysis and a predictor of the prognosis via blood pressure variability. Continuous digital data of blood pressure and heart rate extracted with high sensitivity may generate new biological information that connects hemodynamics, autonomic nervous function, and brain function. With the development of high-sensitivity sensors capable of continuous measurement and the development of big data analysis technology using AI, new bioinformatics obtained from blood pressure information is not limited to blood pressure management in hypertensive patients. This technique is expected to be applied to the pre-onset prediction of stroke and myocardial infarction, and prediction of aggravation of heart failure. I hope that telemedicine that manages health will be realized by grasping the pathological condition based on biological information of blood pressure and not by the mere recording of blood pressure values.

Regarding aging science, we should promote hypertension research from the point of extending healthy lifespan. This means that we should focus not only on the prevention of cardiovascular diseases but also the optimized hypertension control in patients with aging-related diseases such as frailty and dementia which affect activities of daily living in older adults. Various blood pressure regulators and chronic inflammation in tissues associated with hypertension may affect aging, and elucidation of this mechanism is expected to propose new therapeutic targets in hypertensive patients.

\section{The third pillar of "the JSH plan for the future": social enlightenment}

We have planned to develop a society where citizens themselves manage their blood pressure. The JSH announced the "Tokyo Declaration Promoting Salt Reduction by the Japanese Society of Hypertension" in 2019 [5]. We have planned six strategies to reach the target salt intake level of $<6 \mathrm{~g} /$ day. We know that hypertension is not only a lifestyle-related disease but also a food environment-related disease. Besides this action, we encourage to construct model towns where the blood pressure of all citizens is controlled ("Hypertension Zero Town"). To achieve these goals, self-monitoring of blood pressure and selfmonitoring of salt intake would be essential tools. This concept does not change even in the new normal era. However, the strategy may change. The JSH is planning a study to verify whether the blood pressure of the people could be reduced by self-monitoring of the $\mathrm{Na} / \mathrm{K}$ ratio as an index of salt intake, introducing it into health guidance, and creating a social environment where low-salt foods are easily available.

\section{International exchange and globalization of the JSH}

The International Society of Hypertension (ISH) KYOTO 2022 chaired by Professor Hiroshi Itoh, the immediate past president of the JSH, is a good opportunity for us to present recent innovation of hypertension research in the new normal era by the JSH and our members. We are grateful that all Asian countries have engaged to commit actively to ISH2022 KYOTO. In the statement of "Kyoto declaration on hypertension research in Asia", we have aspired to generate novel solutions for common hypertension-related problems in Asia based on a deeper understanding of Asian hypertension through cooperative efforts [6]. By ISH2022 KYOTO, we would like to share issues related to hypertension in Asia, discuss the weaknesses of countermeasures in each country, and develop a guide to support each other. The ISH2022 will focus on innovation, advanced technology, and health promotion including food, exercise, and AI dimensions [7]. Although this welcome message was released before the COVID-19 epidemic, all topics are still important even after/with the COVID-19 epidemic as described above. All members of the JSH look forward to seeing participants from all over the world and discussing 
the progress of "the JSH plan for the future" conscious of new normal after/with COVID-19.

\section{Compliance with ethical standards}

Conflict of interest The author declares that he has no conflicts of interest.

Publisher's note Springer Nature remains neutral with regard to jurisdictional claims in published maps and institutional affiliations.

\section{References}

1. Node K, Kishi T, Tanaka A, Itoh H, Rakugi H, Ohya Y, JSH Future Plan Working Group and Executive Board Members, et al. The Japanese Society of Hypertension-Digest of plan for the future. Hypertens Res. 2018;41:989-90.
2. Itoh H. Greeting Messages from President of Japanese Society of Hypertension (JSH) The challenge of JSH: moonshot for "Conquest of hypertension in Japan". Hypertens Res. 2019;42: 925-7.

3. Umemura S, Arima H, Arima S, Asayama K, Dohi Y, Hirooka Y, et al. The Japanese Society of Hypertension guidelines for the management of hypertension (JSH 2019). Hypertens Res. 2019;42:1235-481.

4. Matsuoka R, Akazawa H, Kodera S, Komuro I. The dawning of the digital era in the management of hypertension. Hypertens Res. 2020;43:1135-40.

5. Tsuchihashi T, Ishimitsu T, Ando K, Kusaka M, Ichihara A, Miura $\mathrm{K}$, et al. JSH statement: Tokyo declaration promoting salt reduction by the Japanese Society of Hypertension-the JSH Tokyo declaration. Hypertens Res. 2020;43:1133-4.

6. Ito $\mathrm{M}$, Ishimitsu $\mathrm{T}$, Ichihara $\mathrm{A}$, Itoh $\mathrm{H}$, Ohishi $\mathrm{M}$, Ohkubo $\mathrm{T}$, et al. JSH Statement: Kyoto declaration on hypertension research in Asia. Hypertens Res. 2019;42:759-60.

7. Itoh H. The wisdom for conquering hypertension. 2019. https://www.ish2022.org/congress-information/welcome-message/. 